\title{
Optimization and thermal stability of TiAlN/Mo multilayers
}

\author{
C.J. Tavares ${ }^{\mathrm{a}, *}$, C. Vidrago $^{\mathrm{a}}$, L. Rebouta ${ }^{\mathrm{a}}$, J.P. Rivière ${ }^{\mathrm{b}}$, E. Le Bourhis ${ }^{\mathrm{b}}$, M.F. Denanot ${ }^{\mathrm{b}}$ \\ ${ }^{a}$ Depto. de Física, Universidade do Minho, Azurém, 4800-058 Guimarães, Portugal \\ ${ }^{\mathrm{b}}$ Lab. de Metallurgie Physique, Université de Poitiers, 86960 Futuroscope, France
}

Available online 7 April 2005

\begin{abstract}
In this work we focus on the optimization and thermal stability of nanocomposite TiAlN/Mo multilayers that were produced by reactive magnetron sputtering on high-speed steel substrates, with modulation periods below $5 \mathrm{~nm}$. These multilayers were annealed between 600 $900{ }^{\circ} \mathrm{C}$ for $1 \mathrm{~h}$ in a vacuum furnace. Preliminary X-ray results reveal that these coatings are very stable up to $900{ }^{\circ} \mathrm{C}$, since the multilayer chemical modulation is not severely affected. At intermediate annealing temperatures the modulation period decreases due to interdiffusion at the interface, resulting in a thicker interface between metal/nitride and hence decreasing the thickness of those layers.
\end{abstract}

(C) 2005 Elsevier B.V. All rights reserved.

Keywords: Multilayers; Thermal stability; Hardness; Stress; Roughness; Interdiffusion

\section{Introduction}

Metal-ceramic modulated layers have proven to be very interesting for particular applications involving tool protection against plastic deformations and subsequent cracking [1-3]. From the many materials that can be chemically modulated in a multilayer, TiAIN is a favourite since it has a reputation for being wear resistant and chemically stable at high working temperatures [4-6]. In this work, we combine the simultaneous deposition of TiAlN ceramic layers with a soft metal, which was chosen to be molybdenum. Previous results by the authors involved static-mode deposition of both materials, however in a controlled and different atmosphere [7]. This proved to be very time-consuming, hence not very interesting for industrial applications. Therefore the quest to produce the alternating layers of TiAlN/Mo in a combined $\mathrm{Ar} / \mathrm{N}_{2}$ atmosphere became a difficult task since one had to minimise the reaction of Mo with nitrogen, in order to minimise the formation of $\mathrm{MoN}_{x}$ phase at the interface, which would soften and induce roughness at the interfaces.

\footnotetext{
* Corresponding author.

E-mail address: ctavares@fisica.uminho.pt (C.J. Tavares).
}

\section{Experimental details}

The $\mathrm{Ti}_{0.4} \mathrm{Al}_{0.6} \mathrm{~N} / \mathrm{Mo}$ multilayer coatings were deposited on high-speed steel (AISI M2) substrates using a custom made reactive sputtering automated system, operating in rotation mode for simultaneous deposition of both layered materials, with the experimental conditions presented on Table 1. Additional information on this experimental deposition process can be encountered elsewhere [8].

XRD $\theta-2 \theta$ scans, both in symmetric and asymmetric modes, were performed using Brucker AXS D5005 and Philips X-Pert diffractometers with $\mathrm{Cu}-\mathrm{K} \alpha$ radiation. The low-angle XRD refinement program Suprex [9,10], using the optical theory developed by Underwood and Barbee [11], was used as a fitting procedure that enabled a precise determination of the relative thickness of each material in a bilayer, interdiffusion width $\left(t_{\mathrm{id}}\right)$ at the interface and the overall interfacial roughness $\left(\sigma_{\text {rms }}\right)$, being its calculation procedure described elsewhere by the authors [7].

The attenuation of the intensity $(I)$ for the first order Bragg peaks in the low-angle XRD profiles as a function of the annealing time can be related with interdiffusivity across the interfaces by the following equation [12]:

$\frac{\mathrm{d} \ln I}{\mathrm{~d} t}=-\frac{8 \pi^{2}}{\Lambda^{2}} D$ 
Table 1

Important deposition parameters for the simultaneous reactive sputtering deposition of the $\mathrm{Ti}_{0.4} \mathrm{Al}_{0.6} \mathrm{~N} / \mathrm{Mo}$ multilayers

\begin{tabular}{ll}
\hline Base pressure & $1 \times 10^{-5} \mathrm{~Pa}$ \\
Argon partial pressure & $0.35 \mathrm{~Pa}(55 \mathrm{sccm})$ \\
Nitrogen partial pressure & $0.1 \mathrm{~Pa}(12.5 \mathrm{sccm})$ \\
Temperature during deposition & $250{ }^{\circ} \mathrm{C}$ \\
Target-to-substrate distance & $65 \mathrm{~mm}$ \\
Bias voltage & $-70 \mathrm{~V}$ \\
Ti cathode current & $2 \mathrm{~A}$ \\
Mo cathode current & $0.9 \mathrm{~A}$ \\
Film thickness & $\sim 4 \mu \mathrm{m}$
\end{tabular}

where $t$ is the annealing time, $\Lambda$ represents the multilayer's modulation period and $D$ the interdiffusivity coefficient. $D$ depends on the composition and hence is very influenced by the formation of a solid solution at the interfaces.

Transmission electron microscopy observation in highresolution mode was performed using a JEOL 3010 equipment with accelerating voltages of $300 \mathrm{kV}$. The coating hardness was determined from the loading and unloading curves carried out with an ultra low loaddepth sensing nanoindenter from CSM, with a load of 30 $\mathrm{mN}$, a loading time of $30 \mathrm{~s}$, a creep time of $30 \mathrm{~s}$, similar unloading time and an average of 15 indentations per sample. An established method of assessing the adhesion of hard coatings is the scratch test, being its description and test method described elsewhere [13]. The technique used for the residual stress measurement was based on the associated curvature deflection of a thin substrate and Stoney's formulism [14]. In order to study the thermal stability of the $\mathrm{Ti}_{0.4} \mathrm{Al}_{0.6} \mathrm{~N} / \mathrm{Mo}$ multilayers, these coatings were annealed between $600-900{ }^{\circ} \mathrm{C}$ for $1 \mathrm{~h}$ in a vacuum furnace with a base pressure of $1 \times 10^{-4} \mathrm{~Pa}$.

\section{Results and discussion}

Previous work on Rutherford backscattering spectroscopy (RBS) experiments and corresponding simulations [15] extracted the composition of (Ti,Al)N thick samples deposited in the same conditions as the multilayers. From this study it was concluded that the composition of the nitride is $\mathrm{Ti}_{0.4} \mathrm{Al}_{0.6} \mathrm{~N}$ ( $\mathrm{B} 1 \mathrm{NaCl}$ fcc type structure).

Fig. 1 shows $\mathrm{X}$-ray diffraction profiles in high-angles for the as-deposited $\left(250{ }^{\circ} \mathrm{C}\right) \mathrm{Ti}_{0.4} \mathrm{Al}_{0.6} \mathrm{~N} / \mathrm{Mo}$ multilayer sample and also after annealing in vacuum for $1 \mathrm{~h}$ at 600,800 and $900{ }^{\circ} \mathrm{C}$; the modulation period is $\sim 5 \mathrm{~nm}$. From these XRD patterns one can see that there is a slight shift of the multilayer satellite peaks to higher angles, mainly due to the relaxation of the compressive stresses inside the coatings (see Table 2). The intensity of the satellite peaks is reduced and these become less resolved with the increase of the anneal temperature up to $800{ }^{\circ} \mathrm{C}$, due to the fact that at this temperature we are enhancing interdiffusion kinetics at the interfaces between the nitride and metal layer. However, the satellite peaks regain their resolution at $900{ }^{\circ} \mathrm{C}$ due to a recrystallisation process.

In Fig. 2, from the evolution of the calculated interdiffusion width $\left(t_{\mathrm{id}}\right)$ and rms roughness $\left(\sigma_{\mathrm{rms}}\right)$ at the interfaces with the annealing temperature in vacuum one concludes that the increase in temperature leads to a higher structural disorder at the interfaces. Most of the rms roughness derives from the interdiffusion that is thermally activated through the interfaces. Nevertheless, at $900{ }^{\circ} \mathrm{C}$, and due to aforementioned recrystallisation process, the interfaces become sharper. The resolved modulation period decreases with the annealing temperature since the interfaces become thicker.

A high-resolution transmission electron microscopy (HRTEM) image from the cross-section of an as-deposited $\mathrm{Ti}_{0.4} \mathrm{Al}_{0.6} \mathrm{~N} / \mathrm{Mo}$ multilayer sample with a modulation period of $2.9 \mathrm{~nm}$ is shown in Fig. 3. From the cross-section analysis one can see that, despite the interfaces being diffused, there is a noticeable coherency between the crystalline planes of both materials. For the same modulation periods, these interfaces possess more structural disorder (roughness resulting from intermixing) than those from static-mode grown multilayers [7]. Possibly due to the formation of a $\mathrm{MoN}_{x}$ solid solution phase at the interfaces. The inset selected area electron diffraction (SAD) pattern in Fig. 3 also yields information relative to the multilayer texture, which happens to be dominated by the growth of f.c.c TiAlN (200) and b.c.c. Mo (110) planes.

Due to the $24 \%$ lattice mismatch between both types of crystals, we have concluded on a previous work [7] that in order to maintain the crystalline coherence across the interfaces the crystals had to undergo a $45^{\circ}$ rotation; nevertheless a mismatch of $\sim 7 \%$ is inevitable. This leads to a deformation of the interplanar spacing and therefore to the superposition of the main textured diffraction rings of both materials on the SAD pattern. The miscible structural disorder found at the interfaces also influences the broad-

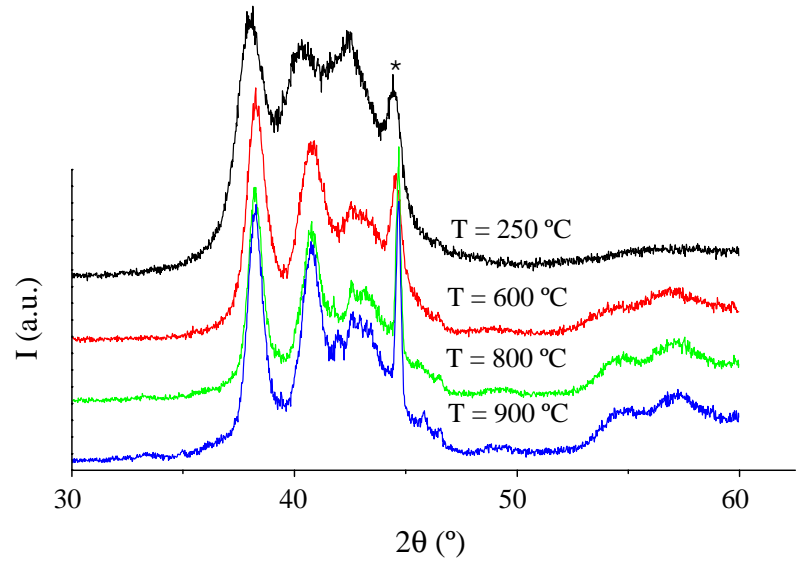

Fig. 1. XRD profiles in high-angles for the as-deposited $\left(250{ }^{\circ} \mathrm{C}\right)$ $\mathrm{Ti}_{0.4} \mathrm{Al}_{0.6} \mathrm{~N} / \mathrm{Mo}$ multilayer sample and after annealing for $1 \mathrm{~h}$ at 600,800 and $900{ }^{\circ} \mathrm{C}$ in vacuum; the average modulation period is $\sim 5 \mathrm{~nm}$. The asterisk denotes the high-speed steel substrate contribution. 
Table 2

Modulation period $(\Lambda)$, nitrogen flow $\left(\mathrm{N}_{2}\right)$, hardness $(H)$, Young's modulus $(E)$, biaxial residual stress $(\sigma)$, adhesion critical load $\left(L_{\mathrm{c}}\right)$ and interdiffusivity coefficient $(D)$ for a set of $\mathrm{Ti}_{0.4} \mathrm{Al}_{0.6} \mathrm{~N} / \mathrm{Mo}$ multilayers deposited with the conditions listed in Table 1 , except for the variable nitrogen flow

\begin{tabular}{|c|c|c|c|c|c|c|}
\hline$\Lambda(\mathrm{nm})$ & $\mathrm{N}_{2}(\mathrm{sccm})$ & $H(\mathrm{GPa})$ & $E(\mathrm{GPa})$ & $\sigma(\mathrm{GPa})$ & $L_{\mathrm{c}}(\mathrm{N})$ & $D\left(\mathrm{~m}^{2} / \mathrm{s}\right)$ \\
\hline 2.9 & 12.5 & $27 \pm 3$ & $297 \pm 22$ & $-2.1 \pm 0.1$ & $74 \pm 5$ & - \\
\hline 3.5 & 12.5 & $26 \pm 3$ & $256 \pm 18$ & $-2.0 \pm 0.3$ & $56 \pm 3$ & - \\
\hline 3.9 & 12.5 & $26 \pm 2$ & $278 \pm 19$ & $-1.8 \pm 0.3$ & $59 \pm 6$ & - \\
\hline 5.0 & 12.5 & $25 \pm 2$ & $286 \pm 11$ & $-1.6 \pm 0.1$ & $60 \pm 3$ & - \\
\hline 5.0 & 14 & $24 \pm 2$ & $261 \pm 10$ & $-3.9 \pm 0.2$ & - & $1.3 \times 10^{-22}$ \\
\hline 5.0 & 15.5 & $26 \pm 2$ & $280 \pm 14$ & $-3.4 \pm 0.4$ & - & $7.8 \times 10^{-23}$ \\
\hline 5.0 & 17 & $27 \pm 2$ & $292 \pm 10$ & $-3.1 \pm 0.1$ & - & $2.5 \times 10^{-23}$ \\
\hline 5.0 & 18.5 & $28 \pm 1$ & $276 \pm 14$ & $-2.7 \pm 0.1$ & - & $3.6 \times 10^{-23}$ \\
\hline 5.0 & 20 & $28 \pm 2$ & $300 \pm 10$ & $-1.6 \pm 0.4$ & - & $6.7 \times 10^{-23}$ \\
\hline 5.0 & 21.5 & $22 \pm 2$ & $250 \pm 15$ & $-0.8 \pm 0.1$ & - & $1.2 \times 10^{-22}$ \\
\hline
\end{tabular}

ening and overlapping of the rings on the SAD pattern in the inset of Fig. 3. From the angular distribution of the arcs inside the diffraction ring one concludes that the grain texture disorientation for this sample is particularly high, being of the order of $20^{\circ}$ about (200). From XRD asymmetric $\alpha$-scans on a sample with a slightly higher modulation period $(\sim 5 \mathrm{~nm})$ the variation of the fibre axis yielded a slightly lower disorientation of $12^{\circ}$, possibly due to the fact that for very small periods there is an enhancement of the intermixing between both layered materials, which contributes to a larger waviness from the interfaces. Thus, both techniques yielded a relatively high level of disorientation of the main textured grains, particularly due to the enhanced roughness and large-scale waviness that result from the miscible interfaces.

In Table 2 a list of the most important mechanical properties for two sets of $\mathrm{Ti}_{0.4} \mathrm{Al}_{0.6} \mathrm{~N} / \mathrm{Mo}$ multilayers are shown. In the upper part of this table, a set of multilayers deposited with the same conditions as those stated in Table 1 but with different modulation periods between 2.9 and $5 \mathrm{~nm}$ are presented together with their respective hardness, Young's modulus, biaxial residual stress and adhesion critical load. Upon comparing the hardness of these samples with the ones deposited on static-mode [7], one clearly sees the maximum hardness is half of what was expected. This decrease in hardness is related to a $\mathrm{MoN}_{x}$ solid solution that

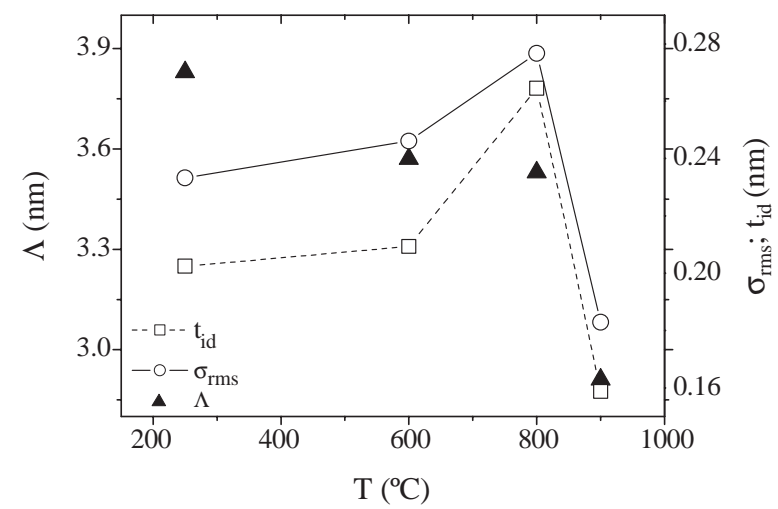

Fig. 2. Evolution of the modulation period $(\Lambda)$, interdiffusion width $\left(t_{\text {id }}\right)$ and rms roughness $\left(\sigma_{\text {rms }}\right)$ at the interfaces for a set of $\mathrm{Ti}_{0.4} \mathrm{Al}_{0.6} \mathrm{~N} / \mathrm{Mo}$ multilayers with increasing annealing temperature in vacuum. is formed at the interfaces. Recent RBS results on these samples enabled the determination of the composition of the metal (Mo) layers, which resulted in some cases a maximum incorporation of 18 at.\% of nitrogen. This $\mathrm{MoN}_{x}$ formation, which is more critical at the interfaces, as it can be seen from the diffused interfaces from the high HRTEM image in Fig. 3, is responsible for reducing the desired effect of having an alternating ceramic hard layer and a ductile metal layer, as suggested by many authors [16]. Since the Young's modulus is strongly dependent on the chemical composition and since the covalent bonds in nitrides give rise to less elasticity in the material, this combined effect deteriorates the ductile nature of the metallic layer. There is an apparent hardness increase with modulation period decrease, albeit these changes lying within the error margin centred at 26 GPa. An analogous analysis can be performed for the Young's modulus; hence one can almost conclude that in fact both properties are stable within the 2.9-5 nm modulation period range. Same goes for the residual stresses and adhesion critical loads. For a low nitrogen flux (12.5 $\mathrm{sccm}$ ), the biaxial residual stress is compressive, possessing

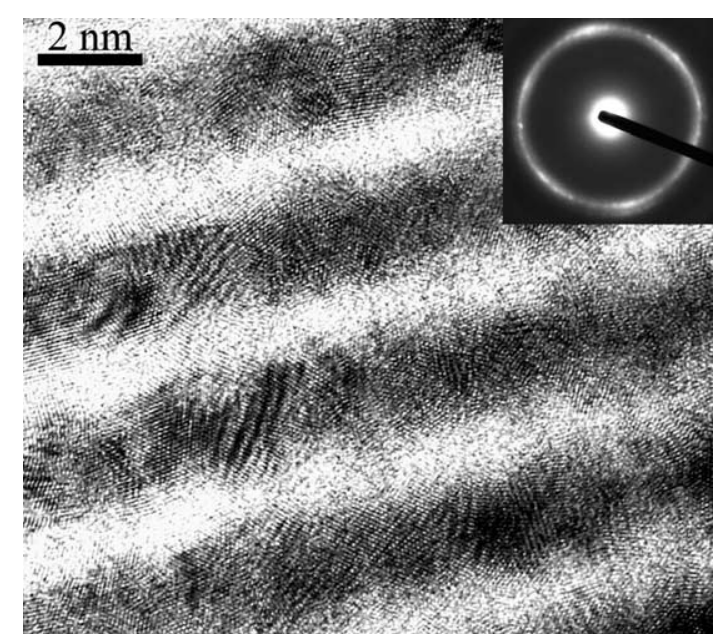

Fig. 3. HRTEM image from the cross-section of an as-deposited $\mathrm{Ti}_{0.4} \mathrm{Al}_{0.6} \mathrm{~N} / \mathrm{Mo}$ multilayer sample, with a modulation period of $2.9 \mathrm{~nm}$. The SAED on the inset indicates the preferential growth of the (200) nitride layers. The darker layers are associated with Mo due to this material's higher scattering factor. 


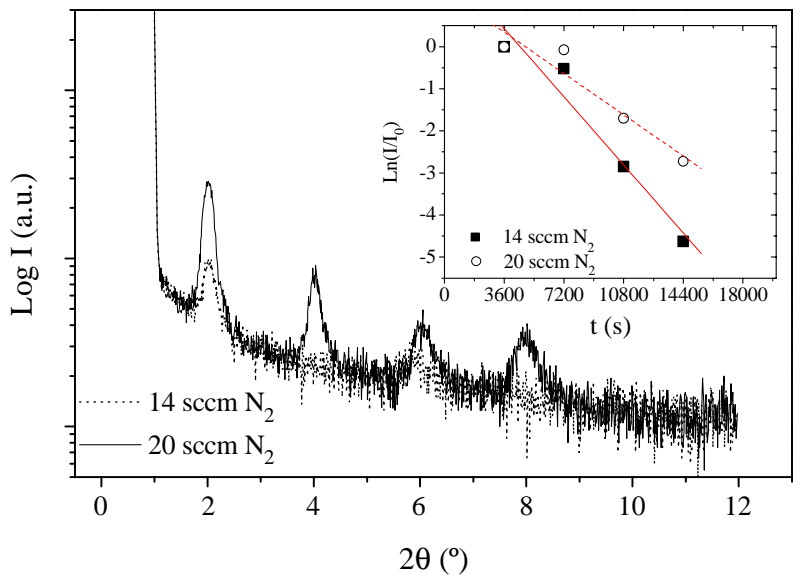

Fig. 4. XRD profiles in low-angles for two $\mathrm{Ti}_{0.4} \mathrm{Al}_{0.6} \mathrm{~N} / \mathrm{Mo}$ multilayer samples, with a modulation period of $\sim 5 \mathrm{~nm}$ and with different $\mathrm{N}_{2}$ flows (14 and $20 \mathrm{sccm}$ ), annealed at $800{ }^{\circ} \mathrm{C}$ in vacuum for $4 \mathrm{~h}$. The inset represents the $\ln \left(I / I_{0}\right)$ plot of Eq. (1) versus annealing time at $800{ }^{\circ} \mathrm{C}$ for both nitrogen fluxes.

moderate values (for a $\sim 4 \mu \mathrm{m}$ thick coating) that are lower than the ones obtained for the static-mode grown multilayers [7]; which for this period ranged between -3 and -4 $\mathrm{GPa}$. This reduction in half of the compressive residual stress benefits the mechanical properties of the multilayer by lowering the build-up stress state and hence reducing the tendency of spallation upon plastic deformation when performing the adhesion tests. These adhesion tests yielded critical loads in the range of 60-70 $\mathrm{N}$, which are slightly higher than the ones obtained in the low-modulation period static-mode grown multilayers.

In the lower part of Table 2 these mechanical properties were revaluated for a set of $\mathrm{Ti}_{0.4} \mathrm{Al}_{0.6} \mathrm{~N} / \mathrm{Mo}$ multilayers grown with similar conditions (see Table 1), except for an increasing nitrogen flow from 12.5 to $21.5 \mathrm{sccm}$. As the nitrogen flux increased up to $20 \mathrm{sccm}$ a moderate hardness increase from 25 to $28 \mathrm{GPa}$ was observed, following by a rapid decrease in hardness for a $21.5 \mathrm{sccm}$ flow. The Young's modulus follows irregularly this trend, having a maximum value of $300 \mathrm{GPa}$. Conversely, the residual stress decreased with an increase in the nitrogen flux, having a minimum of $-0.8 \mathrm{GPa}$ for the highest flux. Further HRTEM instigations will unveil if this residual stress drop with the nitrogen increase is related to the enhancement of shaper interfaces, hence lower structural disorder and coherent strains at the interfaces and therefore less residual stress.

Fig. 4 depicts $\mathrm{X}$-ray diffraction profiles in low-angles for two $\mathrm{Ti}_{0.4} \mathrm{Al}_{0.6} \mathrm{~N} / \mathrm{Mo}$ multilayer samples, with different $\mathrm{N}_{2}$ flows (14 and $20 \mathrm{sccm}$ ), annealed at $800{ }^{\circ} \mathrm{C}$ in vacuum for $4 \mathrm{~h}$. It is clear the intensity of the Bragg peaks increase with the $\mathrm{N}_{2}$ flux, since the Bragg peaks become better resolved and thus revealing a better chemical modulation in the multilayer stacking. The inset in this last figure represents the $\ln \left(I / I_{0}\right)$ plots of the first order Bragg peak versus annealing time at $800{ }^{\circ} \mathrm{C}$ for both nitrogen fluxes; from the slopes the interdiffusivity coefficients $(D)$ can be extracted by using Eq. (1). These values are listed in Table 2 , and from these results one concludes the diffusivity is very rapid at very low and largest $\mathrm{N}_{2}$ fluxes, being of the order of $10^{-22} \mathrm{~m}^{2} / \mathrm{s}$, hence the miscible nature of the interfaces and hardness decrease. At intermediate $\mathrm{N}_{2}$ fluxes the diffusivity is slower and of the order of $10^{-23} \mathrm{~m}^{2} / \mathrm{s}$, thus revealing sharper interfaces and hence better mechanical properties.

\section{Conclusions}

By comparing the mechanical and structural properties of both static-mode and simultaneous deposited $\mathrm{Ti}_{0.4} \mathrm{Al}_{0.6} \mathrm{~N} / \mathrm{Mo}$ multilayers we conclude that there is still a lot of work to undergo in order for the latter multilayers to have hardness levels as high as the formers. The mechanism responsible for his results from a possible $\mathrm{MoN}_{x}$ phase that is present at the interfaces, which results from the incorporation of nitrogen in the Mo layers. This incorporation reduces the ductile nature of the Mo layers and thus diminishes the desired effect of anomalous strengthening. Following the annealings in a vacuum furnace it was observed from the XRD patterns that these multilayers are very stable at high temperatures, up to 900 ${ }^{\circ} \mathrm{C}$ where they retain their chemical modulation and structural coherence, despite the higher level of interdiffusion at the interfaces. The interdiffusion decreases with increasing $\mathrm{N}_{2}$ flow up to $20 \mathrm{sccm}$, where the interdiffusivity is of the order of $10^{-23} \mathrm{~m}^{2} / \mathrm{s}$.

\section{Acknowledgements}

The authors gratefully acknowledge the funding from the Portuguese FCT/MCES scientific program.

\section{References}

[1] X. Chu, M.S. Wong, W.D. Sproul, S.A. Barnett, Surf. Coat. Technol. 61 (1993) 251.

[2] G. Abadias, Y.Y. Tse, A. Michel, C. Jaouen, M. Jaouen, Thin Solid Films 433 (2003) 179.

[3] A. Madan, S.A. Barnett, J. Vac. Sci. Technol., A, Vac. Surf. Films 19 (3) (2001) 952.

[4] S.G. Harris, E.D. Doyle, A.C. Vlasveld, J. Audy, D. Quick, Wear 254 (2003) 166

[5] S. Paldey, S.C. Deevi, Mater. Sci. Eng., A Struct. Mater.: Prop. Microstruct. Process. 342 (2003) 58.

[6] N.J.M. Carvalho, E. Zoestbergen, B.J. Kooi, J.Th.M. de Hosson, Thin Solid Films 429 (2003) 179.

[7] C.J. Tavares, L. Rebouta, E. Ribeiro, J.P. Rivière, J. Pacaud, M.F. Denanot, Surf. Coat. Technol. 174-175 (2003) 273.

[8] C.J. Tavares, L. Rebouta, J.P. Rivière, J. Pacaud, H. Garem, K. Pischow, Z. Wang, Thin Solid Films 398-399 (2001) 397.

[9] C.J. Tavares, L. Rebouta, M. Andritschky, F. Guimarães, A. Cavaleiro, Vacuum 60 (2001) 339. 
[10] E.E. Fullerton, I.K. Schuller, H. Vanderstraeten, Y. Bruynseraede, Phys. Rev., B 45 (1992) 9292.

[11] J.H. Underwood, T.W. Barbee, Appl. Opt. 20 (1981) 3027.

[12] A.L. Greer, F. Spaepen, in: L.L. Chang, B.C. Geissen (Eds.), Synthetic Modulated Structure Materials, Academic Press, New York, 1985.

[13] P.J. Burnett, D.S. Rickerby, Thin Solid Films 54 (1987) 403.
[14] G.G. Stoney, Proc. R. Soc. Lond., A 82 (1909) 172.

[15] C.J. Tavares, L. Rebouta, E. Alves, N.P. Barradas, J. Pacaud, J.P. Rivière, Nucl. Instrum. Methods Phys. Res., B Beam Interact. Mater. Atoms 188 (2002) 90.

[16] B.M. Clemens, H. Kung, S.A. Barnett, MRS Bull. 24 (2) (1999) 20. 